\title{
ENTREVISTA COM ALEXANDRE BARBOSA DE SOUZA
}

\author{
Patrícia Rodrigues Costa 1 \\ -Universidade de Brasília, Distrito Federal, Brasília, Brasil
}

Rodrigo D’Avila Braga Silva²

${ }_{2}^{2}$ Universidade Federal de Santa Catarina, Florianópolis, Santa Catarina, Brasil

Alexandre Barbosa de Souza é escritor, poeta, editor e tradutor. Foi editor na Editora 34, na Cosac Naify e na Biblioteca Azul. É autor de Azul Escuro (Hedra, 2003), Autobiografia de um super-herói (Hedra, 2003) e Livro geral (Companhia das Letras, 2013). Traduz do inglês, francês e espanhol. Entre suas traduções podese citar: Moby Dick (Cosac Naify, 2008), de Herman Melville; $A$ crônica dos Wapshot (Companhia das Letras, 2011), de John Cheever; Orgulho e Preconceito (Companhia das Letras, 2011) e Razão e Sensibilidade (Companhia das Letras, 2012), de Jane Austen; Alice através do espelho (SESI-SP, 2018); Só garotos (Companhia das Letras, 2018), de Patti Smith; Anne de Green Gables (Editora Nova Fronteira, 2019), de L. M. Montegomery.

[CT] Cadernos de Tradução: Você é escritor, poeta, editor e tradutor. Como você começou a traduzir?

[ABS] Alexandre Barbosa de Souza: Comecei adolescente traduzindo letras de música do inglês (Bob Dylan), do francês (Jacques Brel) e do espanhol (Mercedes Sosa, Violeta Parra), com dicionários. Passei a traduzir poetas de que eu gostava para fanzines (Kenneth Rexroth, Jules Supervielle, Nicanor Parra). Mas minha primeira 
tradução profissional foi um romance juvenil da Ros Asquith, I was a teenage worrier, que traduzi como Eu era uma adolescente encanada - que talvez já seja um adjetivo datado...

[CT]: Você tem um perfil de autores ou estilos literários que você tem preferência para traduzir??

[ABS]: Traduzi mais ficção do século XIX (de Jane Austen, Lewis Carroll e Bram Stoker, por exemplo, já traduzi dois livros de cada); já traduzi alguma prosa literária do século XX (como John Cheever, Alice Munro, Edward Gorey, René Crevel), e recentemente tenho traduzido autores do século XXI (como Kent Haruf, John Williams, Blexbolex, Blutch). Acho que prefiro o século XIX, mas sou totalmente século XX - o século XXI ainda não faz muito a minha cabeça.

[CT]: Em entrevista ao site Como eu escrevo, você afirmou traduzir o texto completamente para em seguida revisar, fazendo anotações enquanto revisa e após enviar para a editora você pede para que enviem o texto diagramado para reler mais uma vez. E, por vezes, dá uma cópia da tradução a algum amigo para ler. Como a sua experiência como editor e profundo conhecedor do processo editorial, interfere no seu processo tradutório?

[ABS]: Minha experiência como editor, em geral, facilita a vida da editora que contrata a tradução; costumo avisar dos problemas que aparecem e comentar as etapas do trabalho - desdobramentos e inter-relações da obra que podem interessar na edição. Por exemplo, recentemente, traduzi $O$ retrato de Dorian Gray e aproveitei para traduzir um artigo do James Joyce sobre o Oscar Wilde, que sugeri e a editora incluiu como posfácio. 
[CT]: Como você estabelece o seu projeto de tradução para cada obra que você tem intenção de traduzir e qual o seu processo de pesquisa em torno delas?

[ABS]: Em geral, as editoras propõem prazos de dois a quatro meses, para esses romances do século XIX - é uma loucura, do ponto de vista acadêmico. Costumo traduzir entre 5 e 10 laudas por dia de trabalho, trabalho de domingo a sábado, das $7 \mathrm{~h}$ às $17 \mathrm{~h}$. Depois, vou aos sebos - nos últimos dois anos, tenho passado praticamente toda tarde na Loplop - melhor livraria de São Paulo - e tudo o que preciso encontro por lá ou eles encontram para mim. Enquanto estou traduzindo, procuro ler tudo o que encontro. Depois que consegui acesso livre ao JSTOR e graças à Library Genesis, realmente não preciso mais da universidade.

[CT]: Você utiliza alguma ferramenta de apoio à tradução (memoQ; Trados; WordSmith tools)? Quais os prós e contras ao uso destas ferramentas para a tradução literária?

[ABS]: Nunca usei. Não saberia dizer. Acho até bom quando reincido nas mesmas dúvidas, acabo anotando as palavras de que sempre esqueço um significado, e com isso vou construindo a minha própria memória de tradução nos meus caderninhos.

[CT]: Qual(is) a(s) obra(s) você se sentiu mais desafiado durante o processo tradutório? Por quê?

[ABS]: O Moby-Dick foi sem dúvida o mais difícil, mas eu tinha a Irene Hirsch para ajudar. Talvez o mais desafiador tenha sido $A$ morte difícil, do René Crevel, um escritor surrealista, com uma frase dificílima, longa e entrecortada. É um romance de 1926, com gírias gays de época, digressões e ênfases peculiares. 
[CT]: Algumas traduções realizadas por você são traduções comentadas. Como você enxerga o papel desses comentários para a construção final do texto e como influenciam o processo de leitura do leitor? Como você entende o papel dessa "voz do tradutor" dentro do texto?

[ABS]: Fiz duas edições anotadas para a Zahar, que considero meus melhores trabalhos até hoje: Os livros da selva, do Rudyard Kipling, e Drácula, do Bram Stoker. Em geral, o tradutor não deve comentar muito, mas esclarecer ou apontar apenas, sem desviar a leitura. Aquela ideia do Nabokov de notas de tradução que ocupassem mais espaço da página do que o texto traduzido é ainda um sonho. Recentemente, fiz uma edição do poema $A$ viagem, do Charles Baudelaire, com uma estrofe por página da direita, e uma nota por página da esquerda, mas isso é raríssimo de acontecer, e eu mesmo fiquei mais de dez anos juntando essas notas.

[CT]: A primeira tradução para o português do Brasil da obra Anne of Green Gables data de 1939 de autoria de Yolanda Vieira Martins pela Companhia Editora Nacional publicada na Coleção Biblioteca das Moças. Em 2009, a segunda tradução para o português brasileiro realizada por Maria do Carmo Zanini e Renée Eve Levie foi publicada pela Martins Fontes e em 2015 a terceira tradução por Tully Ehlers foi publicada pela Pedrazul Editora. Em 2019, além da sua tradução para a Editora Nova Fronteira, outras três traduções foram publicadas (por João Sette Camara pela Ciranda Cultural; por Márcia Soares Guimarães pela Autêntica; por Anna Maria Dalle Luche pela Marin Claret). Como você percebe esse movimento de redescoberta da obra Anne of Green Gables, você vê algum fator além da série Anne with an $E$, produzida pela Canadian Broadcasting Corporation $(C B C) e$ disponibilizada em streaming pela Netflix, ou seria somente esse movimento de popularização da obra por meio das adaptações para mídias eletrônicas e digitais? 
[ABS]: A série da CBC é muito boa, acho que ajudou a despertar alguns leitores novos da Montgomery. Acho que o Monteiro Lobato bebeu muito dessa fonte, assim como no Kipling e no Mark Twain. Traduzi os três e fiquei com essa impressão, talvez um dia escreva sobre isso. No caso de Anne de Green Gables, a própria construção da personagem e do cenário de Avonlea lembra muito as do Sítio do Pica-pau Amarelo. Quero dizer com isso que, mesmo a reboque da popularização midiática, existem raízes comuns com a tradição brasileira da literatura dessas importações cristalizadas pelo Lobato.

[CT]: Como você descreveria seu projeto tradutório desta obra de Montgomery?

[ABS]: Como costumo fazer, traduzi o livro sem interrupções nos primeiros dois meses do prazo, e passei mais um mês lendo a tradução impressa e redigindo as notas definitivas.

[CT]: Quais elementos você considera como essenciais para a construção do universo de Anne of Green Gables na tradução? Quais marcas estilísticas da autora você também considera essenciais à tradução?

[ABS]: Em se tratando do século XIX, considero importante não haver anacronismos verbais na tradução, o que é difícil nos diálogos de crianças. A Montgomery é uma mestra nesses diálogos.

[CT]: Sua tradução Anne de Green Gables faz parte da Coleção Elefante direcionada ao público juvenil. Houve alguma adaptação na sua tradução devido ao público alvo do selo editorial em que a sua tradução foi publicada?

[ABS]: Não houve nenhuma adaptação. 
[CT]: As 33 notas de rodapé encontradas no texto são de sua autoria. Por que inserir notas de rodapé? Como você enxerga o papel/influência das suas notas de rodapé no processo de leitura de um leitor jovem?

[ABS]: São quase todas notas identificando passagens literárias acho importante que o leitor perceba que há todo um cânone de leituras esquecido (quem lê Alexander Pope ou Elizabeth Browning hoje em dia?). Além disso, procuro identificar sempre as passagens bíblicas e as canções populares citadas.

[CT]: Você lê outras traduções da obra que pretende traduzir? Você leu alguma tradução de Anne of Green Gables? Se sim, quais foram e como essas traduções anteriores a sua influenciaram na sua tradução e no seu processo tradutório?

[ABS]: Quando traduzi Walden, do Thoreau, eu mesmo já tinha lido três traduções. Mas em geral não fico cotejando enquanto traduzo. No caso da Anne de Green Gables, não li nenhuma outra tradução.

[CT]: Você acha que para traduzir poesia é necessário ser poeta? Por que?

[ABS]: Não é necessário ser poeta. O que ocorre é que muitos poetas são os principais leitores de alguns poetas, e os poetas acabam se dedicando a seus autores de predileção e tentam reescrevê-los com vozes mais incorporadas talvez.

[CT]: Qual seria seu conselho aos tradutores em formação que desejam trabalhar com textos literários? 
[ABS]: Traduza o que você ama.

[CT]: Por fim, quais os caminhos que você indica para melhor compreender (formação) e ingressar no mercado editorial?

[ABS]: Ler dos livros do Paulo Rónai, por exemplo, é um grande avanço para quem quer compreender o universo da tradução. Quanto ao mercado editorial, estou afastado há alguns anos, não saberia recomendar nenhum caminho. Talvez o mais prático seja montar um portfólio de traduções - trechos de obras favoritas - e marcar uma visita a alguma editora com a qual se tem interesse de trabalhar. Mas é preciso pensar bem se a pessoa está disposta a dedicar a vida a algo tão mal remunerado quanto a tradução literária. O Boris Schnaiderman me disse uma vez que, pelo menos, é uma atividade na qual a pessoa tende a ficar melhor com a idade.

\section{Referências}

Austen, Jane. Razão e Sensibilidade. Tradução de Alexandre Barbosa de Souza. São Paulo: Companhia das Letras. 2012.

Austen, Jane. Orgulho e Preconceito. Tradução de Alexandre Barbosa de Souza. São Paulo: Companhia das Letras. 2011.

Carroll, Lewis. Alice através do espelho. Tradução de Alexandre Barbosa de Souza. São Paulo: SESI-SP Editora. 2018.

Cheever, John. A crônica dos Wapshot. Tradução de Alexandre Barbosa de Souza. São Paulo: Companhia das Letras. 2011. 
Melville, Herman. Moby Dick, ou, A Baleia. Tradução de Irene Hirsch e Alexandre Barbosa de Souza. São Paulo: Cosac Naify, 2008.

Montegomery, L. M. Anne de Green Gables. Tradução de Alexandre Barbosa de Souza. Editora Nova Fronteira. Rio de Janeiro: Editora Nova Fronteira, 2019.

Smith, Patti. Só Garotos. Tradução de Alexandre Barbosa de Souza. São Paulo: Companhia das Letras. 2018.

Souza, Alexandre Barbosa de. Livro geral. São Paulo: Editora Hedra. 2013.

Souza, Alexandre Barbosa de. Azul Escuro. São Paulo: Editora Hedra. 2003.

Souza, Alexandre Barbosa de. Autobiografia de um super-herói. São Paulo: Editora Hedra. 2003.

Recebido em: 17/09/2020

Aceito em: 21/11/2020

Publicado em janeiro de 2021

Patrícia Rodrigues Costa. E-mail: prcosta1986@gmail.com. ORCID: http:// orcid.org/0000-0002-3254-8914.

Rodrigo D’Avila Braga Silva. E-mail: rodrigodavilabraga@gmail.com. ORCID: http://orcid.org/0000-0001-6650-1674. 